\title{
COMPARISON BETWEEN ARPA RADAR AND AIS CHARACTERISTICS FOR VESSEL TRAFFIC SERVICES
}

Bin Lin

Merchant Marine Department, National Taiwan Ocean University, Keelung, Taiwan 20224, R.O.C., blin@mail.ntou.edu.tw

Chih-Hao Huang

Merchant Marine Department, National Taiwan Ocean University, Keelung, Taiwan 20224, R.O.C.

Follow this and additional works at: https://jmstt.ntou.edu.tw/journal

Part of the Business Commons

\section{Recommended Citation}

Lin, Bin and Huang, Chih-Hao (2006) "COMPARISON BETWEEN ARPA RADAR AND AIS CHARACTERISTICS FOR VESSEL TRAFFIC SERVICES," Journal of Marine Science and Technology. Vol. 14: Iss. 3, Article 7.

DOI: $10.51400 / 2709-6998.2072$

Available at: https://jmstt.ntou.edu.tw/journal/vol14/iss3/7

This Research Article is brought to you for free and open access by Journal of Marine Science and Technology. It has been accepted for inclusion in Journal of Marine Science and Technology by an authorized editor of Journal of Marine Science and Technology. 
COMPARISON BETWEEN ARPA RADAR AND AIS CHARACTERISTICS FOR VESSEL TRAFFIC SERVICES

Acknowledgements

We are grateful for the financial support offered by the National Science Council, Taiwan, R.O.C. under contract No. NSC 93-2211-E-019-016. 


\title{
COMPARISON BETWEEN ARPA RADAR AND AIS CHARACTERISTICS FOR VESSEL TRAFFIC SERVICES
}

\author{
Bin Lin* and Chih-Hao Huang*
}

Key words: navigation safety, vessel traffic services, ship identity.

\section{ABSTRACT}

Recently most maritime countries in the world have fitted automatic identification system (AIS) in vessel traffic services (VTS) in compliance with regulations of International Convention in order to identify ship name and collect ship information. Traditionally VTS operators use automatic radar plotting aids (ARPA) to get ship maneuvering information for preventing ships from navigational faults. Although the two equipments can provide similar functions for VTS, the operational theory of them is quite different. In this study an experimental observation was carried out by means of ARPA radar and AIS fitted in the building of Merchant Marine Department, NTOU. The detected information was analyzed for comparison of their difference on characteristics. Results reveal that AIS can detect target ships with wider area coverage, larger quantity and more voyage information than ARPA radar. The latter can provide an active monitor to detect small ships that can not be done by AIS. Consequently for navigation safety VTS operators must concentrate on ARPA radar in priority and use AIS as supplementary installation for identification of ships.

\section{INTRODUCTION}

During the past thirty years there has been a considerable increase in the number of merchant ships, and the greatest increase has been in large ships. The result is that more ships and larger ships are congesting in coastal waters and ports, requiring larger maneuvering room at sea. Consequently ships are inevitably exposed to the risk of a collision at sea. Some papers indicated that many marine casualties could be attributed to human error on navigational faults, and most of them were incurred due to incorrect judgment of ship movement or surrounding environment by ship duty officers [1-2, 14]. For improvement of navigation safety and reduction of potential environmental pollution, vessel traffic services (VTS) have been gradually established in many

Paper Submitted 02/08/06, Accepted 03/13/06. Author for Correspondence: Bin Lin.E-mail: blin@mail.ntou.edu.tw.

* Merchant Marine Department, National Taiwan Ocean University, Keelung, Taiwan 20224, R.O.C. large ports and congesting coastal waters in the world in order to help sailing ships to avoid navigational faults. More than 400 of these services have been established in about 50 countries [15].

The International Maritime Organization's (IMO) Guidelines for VTS define VTS as follows [7]:

"A VTS is any service implemented by a competent authority, designed to improve safety and efficiency of traffic and the protection of the environment. It may range from the provision of simple information messages to extensive management of traffic within a port or waterway."

Therefore a VTS is a combination of personnel, operational procedures, equipment, and regulations for the purpose of marine traffic management in a specific water area [9]. Generally one or more of the following services is provided in a port VTS: information service, navigational assistance and traffic organization service [4]. To implement these services, the VTS uses VHF radiotelephone communication and shore-base radar in obtaining data on the identification of ships and their movements.

In accordance with VTS operational procedure, when a ship navigates into the VTS area, the ship officer has to report ship's name, position and voyage information to the VTS center by VHF. The center immediately identifies the ship on radar screen and starts to monitor her movements until the ship completely berths or leaves the area. During her voyage the center provides navigational information to the ship, for example, meteorological conditions in the area, the movements of shipping including fishing ships and the utilization of resources such as tugs, pilots and berths. In case there is any navigational risk to the ship been monitored, the center can transmit a warning or advice regarding the risk to the ship in time. Therefore monitoring the process of a VTS participant has to be done with radar tracking and voice reporting. Ships are identified by means of VHF calls, and then the radar echoes of the ships can be consequently identified.

After automatic radar plotting aids (ARPA) was developed and installed on board in 1980s, course and 
speed of target ships on radar screen could be easily and accurately measured. This function is also convenient for VTS operators to monitor ship movements. Thus ARPA radar has become the necessary equipment for surveillance, and its output data has associated with electronic chart by computer processor in a modern VTS. Although navigational risk can be significantly emphasized on displays in VTS center due to effectiveness of using ARPA radar, the identification of ships by VHF calls occasionally has troubles, such as a mistake of identification, no call from a ship, not in compliance with the requirements, etc., which create potentially dangerous situations and decrease VTS functionality.

The similar problems are also a concern to shipping industry. Many marine collisions could have been possibly avoided if the encountering ships had identified each other and had had good communication by VHF between the ships [3]. In early 1990 some maritime countries developed a new technique, named as automatic identification system (AIS) by IMO in 1996, on automatic transmission and acquisition of ship data and navigational status. Ships equipped with AIS could be more benefit in better information for assessment of dangerous situations. Gradually the AIS has been accepted as an important installation to in modern communication and identification systems for ships. The two-way communication provided by AIS between ships would obvious reduce navigational faults [5]. Thus IMO amended the 1974 Safety of Life at Sea Convention (SOLAS) in 2000. AIS had to be fitted on certain types of ships through a phased implementation period spanning from 1 July 2002 to 1 July 2008.

Following the tragic events of 11 September 2001 in the United States of America, IMO seriously considered that AIS could effectively identify ships which violated navigation regulations or offense against sailing orders through malice, and could prevent the ship in acts of terrorism from entering ports to attack facilities. Due to AIS equipped with GPS function, third party could easily trace a ship position when the AIS signal was transmitted. IMO amended the regulation of SOLAS in 2002 again. The deadline date of AIS fitted onboard was shifted early before the 31 December 2004.

Virtually all commercial ships moving within port waters are the primary users of VTS, and have now fitted with AIS. In general, data received via AIS can enhance the quality of the information available. That is helpful to improve traffic management and navigation safety [11]. The International Association of Lighthouse Authorities (IALA) also suggests the installation of the AIS in VTS that can receive AIS signals to identify ships' name and obtain other navigational status not only through communication by VHF [5]. After AIS is fitted in VTS, operators can obtain ship move- ment information from ARPA radar or AIS, and all information are useful for VTS on traffic management, but most contents of the both data are different except ship course, speed and position. The method of receiving the data in the two equipments is quite different. The old VTS already equipped with ARPA radar has to put AIS on another console table with separated display from the radar. The addition of AIS information for the existing VTS center adds to the problem of information overload.

Let us take Kaohsiung VTS as an example. The AIS display is located about 5 meters apart from the ARPA display because the new AIS system can not be integrated with the old ARPA system. A VTS operator can not simultaneously watch both ARPA display and AIS display. When he identifies ship's name from AIS, probably there is a risk of delaying the surveillance of a navigational fault due to neglect of watching the ARPA display. On the contrary, when concentrating to monitor the ARPA display, he can not realize ship voyage data from AIS, and has to identify ship name through VHF call. For VTS operators, all data via ARPA radar and AIS are important, but only one choice from them for priority at a time. The differences really cause a problem for the safety of navigation. What are the pros and cons of using ARPA radar or AIS?

This paper is focused on the comparison of the difference of function and operation between ARPA radar and AIS through experimental observation, and to find which data should be received first for requirements of VTS operators. The approach of using real ARPA radar and AIS to simultaneously collect navigational data of ships within Keelung port approaches provided a unique method to compare their quality and quantity in this study. Most significantly the observation has enabled evaluation of the accuracy of ship position received from the two equipments. The collected data were analyzed by analysis of variance. And finally, the practical implications of the main results derived from the analysis are addressed in conclusions.

\section{ARPA RADAR FUNCTIONALITY}

Basically ARPA radar is the equipment by means of a computer system operating in conjunction with radar. Radar transmitter generates very short pulses of radio waves. When the waves of one of these pulses encounter any obstacle, such as a ship or shore line, part of the radiated energy is reflected and received by the original radar. The reflected pulse constitutes a radio echo. The time between radiating the pulse and receiving the echo can be accurately measured. Therefore the distance between the radar and the ship is calculated. The direction of the ship is the direction of the pulse 
transmitted [12].

All radar installations should comply with IMO minimum requirements. The variable range marker should enable the range of an object to be measured with an error not exceeding 1.5 per cent of the maximum range of the scale in use, or 70 meters, whichever is the greater. The means provided for bearings should enable the bearing of a target whose echo appears at the edge of the display to be measured with an accuracy of plus or minus 1 degree or better [6].

Traditionally when finding a target echo showing on radar screen, a ship officer plotted the relative motion of the echo in order to get target's course, speed, the closest point of approach (CPA) and the time to CPA (TCPA) by hands. Usually that took much time to complete the plotting task. Owing to the error of remarking the echo's bearing and distance, results of measurement were not very accurate. Sometimes a large mistake in the radar plotting might lead the office to take an incorrect judgment of target ship movements and cause navigational faults. The situation has been improved after ARPA radar fitted onboard. All data are calculated by computer and clearly showed on the ARPA display. The benefit is not only reduction of plotting time in less than 2 minutes for the whole process but also accuracy of the data. Furthermore, ARPA radar can provide navigational warning, when a ship is approaching a defined dangerous area or the CPA to another ship is less than the limited CPA.

Although it is apparent that ARPA radar is a very effective aid to navigation, especially for anti-collision, the limitation of radar function still exists when pulses of radio wave are transmitting. The first is that the maximum distance of an object detected is affected by the height of antenna and the height of object due to the curvature of the earth. Secondarily, some objects, such as small wooden fishing boat, may not be detected until a short distance due to the reflecting power of the pulses affected by the surface and material of the objects. Thirdly, the accuracy of object's bearing is affected by the horizontal beam width of the pulses. In modern marine radar the bearing discrimination is from 0.6 to 2 degrees [10]. Fourthly a more obvious effect is blind areas and shower areas. For radar radiation a mountainous island will cause a blind area, and objects behind the island will not be detected on radar screen. A big ship at close range may cause a shadow, and small objects will not always appear on the screen, especially in a short distance because of the reduction of the echo energy. The shadow effect will reduce the range of a small object detected from 4 miles to 0.5 miles [10]. The loss of tracking will result in the need to reacquire and re-identify. Heavy rain or snow sometimes also affects the effectiveness of radar tracking.
With modern ARPA radar, traffic routes, fairways and other marks of importance can be delineated on the display. No matter the above limitations, ARPA radar currently has become required equipment for surveillance of ship movements in VTS. To achieve the operational purpose the ARPA radar should be able to detect all moving or stationary targets which satisfy the detection criteria within VTS coverage area during all specified operating circumstances. Any target should be acquired and maintain tracking in at least 5 out of every 10 scans average over a period of 2 minutes [9]. Navigation data of target ship should be displayed either on the VTS display using synthetic symbols near the ship or in tabular form in an un-used part of the VTS display. A failure to reacquire a target automatically in a limited time should be brought to the attention of the VTS operator.

\section{AIS FUNCTIONALITY}

Functions of the AIS should satisfy the following requirements: in a ship-to-ship mode for collision avoidance, as a means for littoral States to obtain information about a ship and its cargo, as a VTS tool, i.e. ship-to-shore (traffic management) [8]. The AIS is a shipboard broadcast system operating in the VHF radio maritime frequencies: $161.975 \mathrm{MHz}$ (channel 87B) and $162.025 \mathrm{MHz}$ (channel 88B). The universal VTS using self-organized time division multiple access (SOTDMA) technology was adopted by IMO in 1998 for high broadcast rate and reliable operation. The system is characterized by a transmission schedule. The transmission time in the radio channel is divided into time slots of a constant length. The spacing of the time slots for a particular ship depends on its speed and maneuvering status [3]. AIS is to be capable of handling over 2,000 time slots per minute per channel and updates as often as very two seconds [5].

The AIS should automatically provide to appropriately other ships and shore stations equipped static information, dynamic information and voyage related information. Static information, such as ship call sign, name and Maritime Mobile Service Identity (MMSI) is permanently stored in the AIS. Dynamic information, such as ship's position, course and speed, is collected from ship equipment, such as GPS, gyro compass and speed log. Voyage related information, such as ship's draught and hazardous cargo, is input by ship officers in manually each voyage. It should also receive automatically such information from similarly fitted ship.

The information is autonomously sent at different update rates depending on the type of message. The reporting interval of dynamic information is dependent on speed and course alteration. When a high speed ship 
is changing course, the information update interval is 2 seconds, but it is 3 minutes for the ship at anchor. The interval of static and voyage related information is every 6 minutes or on request [5]. Dynamic information must be apparently sent at a shorter interval than others. The status of ship movement is changing faster the interval of update rate is shorter. Other ship can find the change early. Therefore AIS can provide ship officers with sufficient additional information of the ship encountering that is potentially extremely valuable for taking action to avoid collision.

Every message containing the ship identity is a great value to VTS. Most of ship identifications tracked by VTS rely on approaching ships reporting their name and location through VHF call, and the VTS operator then correlating this information with an unassigned ARPA track. After VTS is fitted with AIS, as the name implies, ship identity can be automatically and immediately provided that help overcome time consuming procedure and misunderstanding messages, inherent in the VHF communications due to the problems of different languages and accents [13]. Another great benefit for VTS is ship tracking improved. VTS receiving AIS messages from a ship at the maximum range of the VHF communications usually in excess of detecting range of conventional radar. As a consequence, VTS can extend detection range and the detection is contained in AIS messages.

The multiple functions of AIS on navigation safety have had a major impact on maritime industry. Although there are many advantages of using AIS receiving ship information: accurate ship position, automatic and prompt update, good quality during adverse weather, reliable ship tracking without shadow effect, etc., there are also some disadvantages in use of AIS. When a ship shuts off the AIS, or does not fit the AIS, such as fishing boats, the VTS operator can see the ship in sight but no information on AIS display. Under this situation, accurately monitoring ship movement could not achieve with AIS, has to use other equipment. If the operation still concentrates on the AIS display and neglects existence of the ship, it will be a seriously critical time. Another problem is that ship equipment in conjunction with AIS, such as GPS or gyro compass, has trouble so that the information delivering to VTS and other ships is incorrect or inaccurate.

\section{EXPERIMENTAL OBSERVATION}

For surveillance requirements VTS must realize ship movements within the severed area. In VTS center, maneuvering information of ships can be detected actively by ARPA radar without the need of transmission by other equipments from target ships, and received passively by AIS because required data have to rely on AIS transmitting from target ships. But the latter can provide ships identity and voyage data automatically. As a VTS operator, facing the two sets of information obtaining from ARPA radar and AIS what should be read first needs a careful consideration. It is necessary to compare which of these two sets of data is more important, useful and accurate for VTS.

Although the effectiveness of receiving data is related to VTS location and ship pattern within the area, it is impossible to use the equipment in VTS for the comparison, which must operate uninterrupted for navigation safety. Therefore it was decide to complement this study by means of experimental observation for obtaining a comprehensive understanding of the effectiveness of data from ARPA radars and AIS fitted in the building of Merchant Marine Department (MMD), National Taiwan Ocean University (NTOU). In the observation, two ARPA radars of JRC maker and two AIS of Nauticast maker were used. The building facing ocean is one mile east off Keelung VTS center. Ships moving within Keelung approaches can be scanned by the ARPA radar and identified by the AIS fitted in the building. Use of the equipments at NTOU provided a unique opportunity to compare present VTS operations in Keelung harbor.

Wave lengths of the two ARPA radars were $3 \mathrm{~cm}$ (X-band) and $10 \mathrm{~cm}$ (S-band) respectively. Therefore during the period of the observation, screens of the two radars were controlled in 6 miles and 24 miles respectively. The maximum number of ship targets detected by the ARPA radars was 6 in manual acquire, and information including bearing, distance, course and speed of three targets could be displayed each time. The information was photographed at 6 minute internal by a digital camera, and then keyed and stored in a computer. Latitude and longitude of target position had to be calculated according to its bearing and distance from the known position of MMD building, as shown in Table 1 .

One of the two AIS equipments was fixed in the building, and another one was a portable. Both AIS were connected with a computer. All received information automatically transferred and stored in the computers with ACCESS data base format, as shown in Table 2 . Because the information of any target ship was received every 2 seconds, the stored information was a large quantity. There were many repeated information or the information with small change for the same target. Therefore the original files of the information in data base had to be sorted out in accordance with the MMSI of target ships. For the comparison with ARPA radar information, each hour was divided into 10 time points so that the information was read in 6 minute 
Table 1. Example of ARPA radar information in the observation

\begin{tabular}{cccccccc}
\hline Obs. no & Time & Latitude & Longitude & Bearing & Dist. & Course & Speed \\
\hline R0128001 & $2005 / 1 / 2809: 06: 00$ & 26.45001231 & 118.5283896 & 326 & 3.5 & 199 & 8.9 \\
R0128002 & $2005 / 1 / 2809: 06: 00$ & 22.59564993 & 124.9850697 & 342 & 4.1 & 154 & 0 \\
R0128003 & $2005 / 1 / 2809: 06: 00$ & 22.04544107 & 124.6067301 & 028 & 4.2 & 300 & 9.3 \\
R0128004 & $2005 / 1 / 2809: 06: 00$ & 29.10156108 & 122.871236 & 051 & 4.1 & 118 & 2 \\
R0128005 & $2005 / 1 / 2809: 06: 00$ & 30.18180072 & 120.946747 & 038 & 5.1 & 145 & 0.3 \\
\hline
\end{tabular}

Table 2. Example of original AIS information in the observation

\begin{tabular}{|c|c|c|c|c|c|c|c|c|c|}
\hline$\overline{\text { Index }}$ & Time & MMSI & $\begin{array}{l}\text { Navigational } \\
\text { status }\end{array}$ & $\begin{array}{l}\text { Position } \\
\text { accuracy }\end{array}$ & Longitude & Latitude & SOG & COG & $\begin{array}{c}\text { True } \\
\text { heading }\end{array}$ \\
\hline 1 & $2005 / 1 / 28$ 08:42:21 & 351056000 & Default & Low & 121.752 & 25.148 & 0 & 150 & 241 \\
\hline 2 & 2005/1/28 08:42:22 & 352388000 & $\begin{array}{l}\text { Under way } \\
\text { using engine }\end{array}$ & Low & 121.752 & 25.145 & 0 & 248 & 511 \\
\hline 3 & 2005/1/28 08:42:23 & 416337000 & $\begin{array}{l}\text { Under way } \\
\text { sailing }\end{array}$ & High & 121.75 & 25.143 & 0 & 103 & 234 \\
\hline 4 & 2005/128 08:42:23 & 538090053 & $\begin{array}{l}\text { Not under } \\
\text { command }\end{array}$ & Low & 121.73 & 25.334 & 0 & 229 & 96 \\
\hline 5 & 2005/1/28 08:42:25 & 416207000 & $\begin{array}{l}\text { Under way } \\
\text { sailing }\end{array}$ & Low & 121.751 & 25.154 & 0 & 47 & 279 \\
\hline
\end{tabular}

Table 3. Example of sorted AIS information in the observation

\begin{tabular}{ccccccccc}
\hline Index & Time & MSSI & Lat. & Long. & Speed & Course & Heading & Distance \\
\hline 2125 & $2005 / 01 / 2809: 00: 00$ & 1130504 & 121.778 & 25.149 & 0 & 0 & 511 & 0.549295003 \\
2124 & $2005 / 01 / 2809: 00: 00$ & 215300000 & 121.724 & 252.0 & 12 & 51 & 130 & 3.9665911 .6 \\
2128 & $2005 / 01 / 2809: 00: 00$ & 309764000 & 121.617 & 25.368 & 16 & 269 & 227 & 15.86499307 \\
2126 & $2005 / 01 / 2809: 00: 00$ & 351056000 & 121.752 & 25.148 & 0 & 178 & 241 & 1.063393154 \\
2127 & $2005 / 01 / 2809: 00: 00$ & 352388000 & 121.752 & 25.145 & 0 & 284 & 274 & 1.116407184 \\
\hline
\end{tabular}

interval. The repeated information, except the first data set, was deleted. The sorted information included time, ship MMSI, latitude longitude, speed, course, heading and distance, as shown in Table 3. The distance was calculated from ship position and the building position. In the Tables 2 and 3, there was a target with heading 511, which represented the AIS installed in the Transportation Department building. To avoid incurring confusion to other ships, the AIS was input a special heading by the Department.

Before the observation, all equipments had to be synchronized with Universal Time Co-ordination (UTC). The observation was divided into two parts. In the first part, the observed targets were moving ships approaching or leaving Keelung port in order to compare the coverage and effectiveness of receiving information in both equipments. It was a 72 hour observation, 36 hours in day time and night time respectively. Through
MapInfo computer software all target position in accordance with their latitude and longitude were plotted on a base chart of coast line with Keelung harbor and adjacent waters. Figures 1 and 2 only show parts of targets near Keelung harbor.

In the second part, the observed target was a fixed target having known accurate location in order to test the accuracy of both equipments. The fixed target at an adequate distance had to be detected by ARPA radars and received by AIS from the MMD building at the same time. Keelung Island was finally chosen as the fixed target. The portable AIS was fitted at Coast Guard building on the island and in conjunction with GPS. The Fixed AIS in the MMD building could receive the position information transmitting form the portable AIS. At mean time the ARPA radars in the building could also monitor the island and detect the bearing and distance of its echo in order to calculate its latitude and 


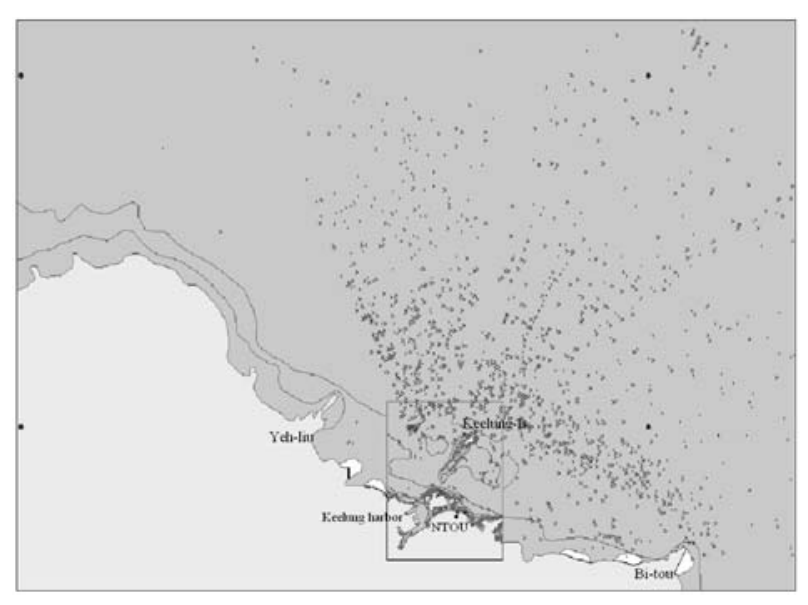

Fig. 1. Locations of targets detected by ARPA radars.

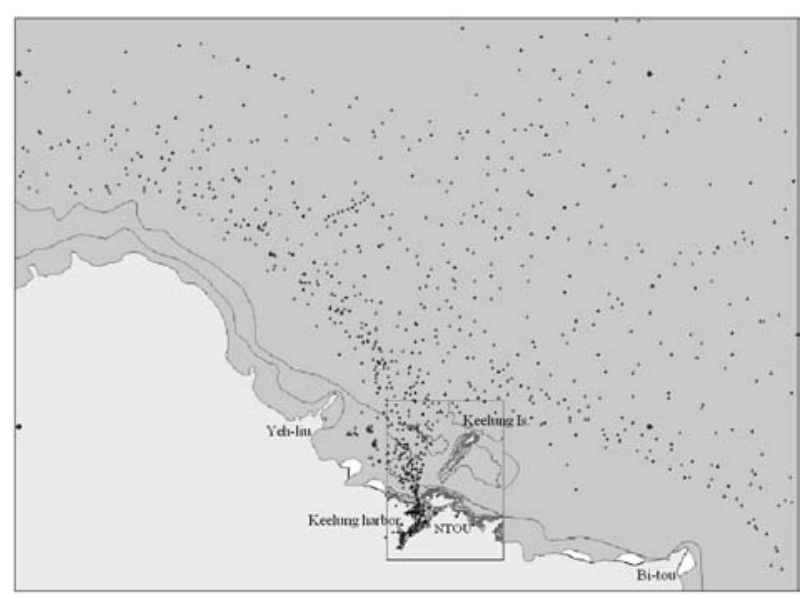

Fig. 2. Locations of targets received by AIS.

longitude. Both positions could be compared to analyze their stability and variety for VTS effectiveness. The criterion of the fixed position was Latitude $25^{\circ} 11.7^{\prime} \mathrm{N}$, Longitude $121^{\circ} 46.7^{\prime} \mathrm{E}$ in accordance with the position of Keelung Island in China Sea Pilot Volume III, published by British Hydrographer of the Navy.

\section{DATA ANALYSIS}

\section{Geographical overage}

The longest target detected by ARPA radars was 33.35 miles in day time, and 29.67 miles in night time. That was 56.16 miles in day time and 46.75 miles in night time by AIS. Because the frequency of radio waves of radar is higher than that of AIS, the distance of the wave transmitting of the former is shorter than that of the latter. Furthermore the detecting distance for ARPA radar is affected by the height of antenna, target's material and size. Therefore the adequate range of ARPA screen in VTS center had better be set within 24 miles. When the target echo is weaker, the range has to be decreased even less than 6 miles, especially for small targets. Relatively, information via AIS can be transmitted to a longer distance due to lower frequency, but the received signal at distance under 40 miles was more clear in the observation. Target's material and size did not affect AIS performance.

\section{Blind area}

It was apparent to find a blind area at north-west coastal waters from Keelung harbor due to obstacle of Ho-pin Island in the observation, as shown in Figure 1. The waters between true bearing 336 degrees from the MMD building and coast line had nearly no targets detected by ARPA. There was also a shadow area behind Keelung Island. The density of targets was less than other areas. After radio waves transmitted by radar met a very close geographical obstacle, Ho-pin Island, the waves could not continuously proceed and reflected back. The screen of the ARPA radar only displayed the obstacle feature without target echo behind the obstacles. AIS tracks could avoid the majority of such effects. Even targets in Keelung harbor which could not be seen in sight from the MMD building were detected, as shown in Figure 2.

\section{No signal target}

When a line connected from Keelung Island to Cape $\mathrm{Bi}$-tou, there were 74 targets within the water area between the line and coast, as shown in Figure 1, but only one target in Figure 2. Water depth of the area is less than 20 meters and shallow water exists from Keelung Island extending to Ho-pin Island. Merchant ships can not navigate in the area, except ships anchoring for awaiting berth. However the area is a good fishery for fishing boats. These boats are exempted to fit AIS from SOLAS. That is the reason why no target could be detected by AIS, but lots of targets be detected by ARPA radars due to active requisition. Furthermore there were probably a few merchant ships turn off their AIS and could not be detected during the period of the observation.

\section{Target quantity}

In the first part of the observation, the average number of total targets detected by AIS was 2,581 ships each day in day time, and the average number at each time point was about 21 ships. By ARPA radars that was 489 ships each day, and 4 ships at each time point. In 
Table 4. Pros (+) and cons (-) of ARPA radar and AIS characteristics

\begin{tabular}{l|l}
\hline \multicolumn{1}{c|}{ ARPA } & \multicolumn{1}{c}{ AIS } \\
\hline (+) Active detection. & $\begin{array}{l}\text { (-) Passive detection. } \\
(+) \text { Effective coverage under 40 nautical miles. } \\
(-) \text { Effective coverage under 24 nautical miles. } \\
\text { (-) Area coverage limited by radar blind and shadow areas. }\end{array}$ \\
$\begin{array}{l}\text { (+) All targets visible. } \\
(-) \text { Total target quantity smaller. }\end{array}$ & $\begin{array}{l}\text { (+) Total target quantity larger and reaching 5 times compared } \\
\text { with ARPA. }\end{array}$ \\
$\begin{array}{l}\text { (+) More voyage information } \\
\text { (+) Position accurate. }\end{array}$ \\
$\begin{array}{l}\text { (+) Position accurate. } \\
(+) \text { Signal stable. }\end{array}$ \\
\hline
\end{tabular}

night time, there were 2,735 ships each day detected by AIS and 499 ships by ARPA radars. The largest number was 30 ships detected by AIS at each time point, and the smallest was 15 ships. But that was 15 ships by ARPA radars, and usually the record was one ship. The target quantity of AIS was about 5.38 times to that of ARPA radars. Generally speaking, factors, such as strength of radio wave detecting range, shadow area and blind area, affecting the detecting quantity of ARPA radars were larger than factors, such as small ships without fitting AIS and large ships turning off their AIS, affecting the quantity of AIS. There was no significant difference between the quantity of targets detected at day time and night time for both equipments.

\section{Contents of information}

Information display on ARPA radars was simple, including ship position, course, speed, bearing, distance, CPA and TCPA. Except position, course and speed, there were some others on AIS display, such as ship MMSI, name, type and navigational status. Some ships transmitted voyage information via AIS, such as ship draught, dangerous cargoes, etc, that depended on the input of ship officers.

\section{Position accuracy}

In the second part of the observation, the standard deviation of latitude and longitude of the fixed target detected by ARPA radars compared with the criterion position was 3.7 meters, and 9.26 meters by AIS. The deviation of both was acceptable. There was no significant difference between the positions of the two equipments. The position in AIS received from GPS was more stable than that in ARPA radars by manual acquired.

Table 4 elucidates the pros and cons of the two equipments from the observation in this study.

\section{CONCLUSION}

For requirements of VTS functions, both ARPA radar and AIS equipments can provide accurate position of detected target ships. AIS can detect a larger number of targets without considering shadow effect and can provide more voyage information for VTS center. ARPA radar can detect targets actively even buoy or rock no matter ship size or fitted any equipment. One of major purpose for VTS is to prevent ships from collision, including a ship colliding with a fishing boat or a buoy. Sometimes fishing boats are working in fairway that obstructs ships moving and increases navigational risk. From AIS information these kinds of situations can not be found so that VTS can not sound collision warning to the related ships. Therefore AIS can not replace ARPA radar in VTS operation.

Although ARPA radar still has deficiency on its characteristics for VTS requirements, some deficiency can be improved. For Keelung VTS, an additional radar is installed in Keelung Island can reduce shadow effect, lessen the blind area and increase the coverage of area and the number of target ships. As for ship identity and voyage information, AIS can be used in VTS center as an auxiliary installation for these functions. From this study the suggestion to VTS is that when a ship moving outside a harbor over 20 miles off, it is necessary to identify her name and receive more information by AIS; after the ship entering the 20 mile boundary, VTS operators have to watch the ARPA display carefully and uninterrupted. Consequently VTS functions can be realized and safety of port water area can be maintained.

\section{ACKNOWLEDGEMENTS}

We are grateful for the financial support offered by the National Science Council, Taiwan, R.O.C. under contract No. NSC 93-2211-E-019-016. 


\section{REFERENCES}

1. Cockcroft, A.N., "Cause Relationships of Collisions and Groundings," The Journal of Navigation, Vol. 35, pp. 305-311 (1982).

2. Drager, K.H., "A Study of Relationships Between Different Causes of Collisions and Groundings," Proceedings of the Third International Marine Traffic Service Symposium, Liverpool, UK, pp. 43-59 (1978).

3. Harre, I., "AIS Adding New Quality to VTS Systems," The Journal of Navigation, Vol. 53, pp. 527-539 (2000).

4. International Association of Lighthouse Authorities (IALA), IALA Ship Traffic Services Manual, France, pp. 27-34 (1993).

5. International Association of Lighthouse Authorities (IALA), Guideline on AIS as a VTS Tool, France, pp. 1-16 (2001).

6. International Maritime Organization (IMO), "Performance Standards for Radar Equipment," IMO Resolution A. 477(XII), pp. 1-5 (1981).

7. International Maritime Organization (IMO), "Guidelines for VTS," IMO Resolution A, Vol. 857, No. 20, pp.
1-18 (1997)

8. International Maritime Organization (IMO), "Recommendation on Performance Standards for a Universal Shipborne AIS," IMO MSC, Vol. 74, No. 69 (1998).

9. Koburger, C.W., Ship Traffic System, Cornell Maritime Press, MD, pp. 1-10 (1986).

10. Liu, Z.T., Radar Observation, Yu-Shih Culture Publication, Taiwan, pp. 149-151 (1983) (in Chinese).

11. Pettersson, B., "Experiences with AIS in Sweden," Proceedings of the 10th Internation Symposium on Ship Traffic Services, Hong Kong, pp. 411-417 (2004).

12. Sonnenberg, G.J., Radar and Electronic Navigation, Newnes-Butterworth, London, pp. 199-270 (1970).

13. Stitt, I.P.A., "AIS and Collision Avoidance - a Sense of Déjà vu," The Journal of Navigation, Vol. 57, pp. 168-180 (2004).

14. Temp, J.F., "Human Factors in Collision Avoidance at Sea," Proceedings of the Third International Maritime Safety Symposium, London, pp. 29-30 (1980).

15. UK Hydrographic Office, Vessel Traffic Services and Reporting System, Admiralty Charts and Publications, UK, NP 287(1) and (2) (1999). 